Ambient Science, 2016: Vol. 03(Sp1); 80-81

DOI:10.21276/ambi.2016.03.sp1.nn01

ambient

SCIENCE

Vol. 3(Sp1):80-81

Year 2016

NOTES ON NATURAL HISTORY

\title{
The Relationship between Lifestyle and Pain in Patients with Spinal Disc Herniation
}

\author{
Monireh Dadashzadeh ${ }^{1}$, Tahereh Nasrabadi ${ }^{1 *}$, \\ Ebrahim Ebrahimi Abianeh ${ }^{2}$ \\ ${ }^{1}$ Department of Nursing, Tehran Medical Sciences Branch, \\ Islamic Azad University, Tehran, Iran \\ ${ }^{2}$ Department of Medical, Tehran Branch, Islamic Azad University, \\ Tehran, Iran
}

\author{
Study Area:Tehran, Iran \\ Coordinates: $35^{\circ} 41^{\prime} 46^{\prime \prime} \mathrm{N}_{51^{\circ}} 25^{\prime} 23^{\prime \prime} \mathrm{E}$
}

Key words: Physical exercise, Psychological factors, Back pain

\section{Introduction:}

Due to the rapid growth of the industries and constantly involvement of the new technologies into the human lives, the lifestyles of the people are altering. Simultaneously few new disorders in their lifestyles and diseases in their lives are also emerging. The spinal cord abnormalities i.e., the spinal disc herniation and/or low back pain is one of them which have made the life of some people very miserable (Farahani et al., 2012). Indeed the overall lifestyle of a human being regulates the musculoskeletal symptoms. Differences in lifestyle and psychosocial factors associated with individuals' lifestyle are effective in experiencing the level of pressure in musculoskeletal systems. Studies related to the lifestyle and musculoskeletal system, including pain and inflammation, are largely correlate (Mikkonen et al., 2015). Proper knowledge regarding the relationship between lifestyle and spinal disc herniation is very important. Social habits such as diet, exercise, weight gain, anxiety, and depression can cause changes in the spinal cord and spinal disc herniation (Kadow et al., 2014). Further, some of the lifestyle parameters such as smoking, nutrition, BMI, level of activity, sleep status, stress, and anxiety are also seen to reduce the need for medication or avoid and reduce musculoskeletal pain (Dean et al., 2015). As per Bohman et al. (2014) people with a healthy lifestyle suffer $66 \%$ less from low back pain than those who have unhealthy lifestyles.

Social scientists consider the lifestyle concept under following aspects: Category 1: Individual factors such as age, BMI, exercise, using alcohol or cigarettes, Category 2: Psychosocial factors, including anxiety, depression, stress and job dissatisfaction, Category 3: Physical and job factors such as repetitive movements and lifting heavy objects. Contemporary studies indicate that occupational factors, especially working conditions and / or working postures are the main causes (Qiao et al., 2014) in addition the various lifestyles have direct impact in spinal disc herniation and the patients' experience of pain (Grotle et al., 2014).

Low back pain caused by spinal disc herniation cause high disruption in the patient's lives. Identifying effective factors associated with pain level and life style of patients with spinal disc herniation is necessary and worthy of attention. In this study we investigate the relationship between lifestyle dimensions (nutrition, exercise program, responsibility for the health, stress management, interpersonal relationships, and spiritual growth) and the degree of pain of patients with lumbar spinal disc herniation referred to selected hospitals of Tehran University of Medical Sciences (2015-16).

\section{OurSurvey:}

Adescriptive-correlational single-group study was carried out in which a total of 200 patients with lumbar spinal disc herniation referred to selected hospitals of Tehran University of Medical Sciences (Imam Khomeini (RA) \& Sina hospitals) were selected by randomly available sampling method. First of all the participants were served to complete the demographic questionnaire followed by health-promoting lifestyle related questionnaire containing 49 questions on 6 dimensions (nutrition, exercise program, responsibility for health, stress management, interpersonal relations and spiritual growth). The level of pain in participants was measured by visual analog scale (VAS) using a $100 \mathrm{~mm}$ ruler. The data were analyzed by using SPSS software, Ver. 22. The inclusion criteria included: Patients with lumbar spinal disc herniation, Patient ages ranged from 18 years up, Patients before surgery.

\section{Our Findings:}

The results on body mass index (BMI) indicated the following findings: $2 \%$ of participants with BMI under 18.5 (underweight), 34\% of participants with BMI between 18.5 to 24.9 (normal weight), $37.5 \%$ of participants with BMI 
between 25 to 29.9 (overweight), $26.5 \%$ of participants with BMI equal to 30 and higher. The highest frequencies were related to BMIs of 23 and 25 , and the average weight of participants was equal to $26.55 \mathrm{~kg}$.

In terms of the visual scale of pain, the results were as follows: $3.5 \%$ in a state of pain (VAS) under 40 degrees, $32.5 \%$ between 50 and 60 degrees, $51.5 \%$ between 70 and 8 o degrees, $12.5 \%$ between 80 and 100 degrees. The mode or highest frequency was related to pain of 70 degrees, and the average pain degree of participants was as 69.30. No significant relationship was found between nutrition status, stress management, interpersonal relationships, spiritual growth, and BMI with the participants' levels of pain. Interestingly, a negative signif icant relationship was evidenced between subjects' exercise program ( sporting activities plan), and their degree of pain (Pearson $=-0 / 154$, $\mathrm{p}<0.029$ ).

\section{Discussion:}

As per Coenen et al. (2013) the personal factors (age, smoking, physical activity or exercise and nutrition), psychological factors (stress, social support and job satisfaction) and physiological factors (bending, lifting heavy subjects and the whole body vibrations) are among such identified risk factors which are responsible for low back pain in people. Nevertheless, osteoarthritis involves degenerative damages, occurring to the disc that causes upper and lower vertebrae reactions of bone and disc growth, which in turn can lead to pressure to inside of the channel (Kadow et al., 2015).

In the lifestyle of people in which nutrition, exercise, stress management, optimism and interpersonal relationships are involved are altogether directly affect the level of pain (Chaman et al., 2015). Social habits, lifestyle etc. can cause changes in the spine and from the spinal injury. Many studies have been conducted to identify the cause and treatment of low back pain. Exercise has been recommended to reduce pain for people with back pain. Physical activity has a potential role in the prevention of chronic low back pain. Therefore, it can be considered as one of the important and essential factors in lifestyle and as one of the effective factors in developing low back pain (Schaller et al., 2015).

Explaining the results, one can say that through choosing a lifestyle to maintain and improve health and prevent diseases, an individual does measures and activities such as observing a proper diet, sleep, and activity, exercise, weight control, non-use of smoking and alcohol and immunization against diseases. Finally, through changing the exercise program and the individuals' responsibility status, the patients would experienceless pain.

Acknowledgements:

Authors are thankful to all the participants who cooperated in this study.

\section{References:}

Bohman, T., Alfredsson, L., Jensen, I., Hallqvist, J., Vingard, E. \& Skillgate, E. (2014): Does a healthy lifestyle behaviour influence the prognosis of low back pain among men and women in a general population? A population-based cohort study. BMJOpen, 4:1-9.

Chaman, R., Aliyari, R., Sadeghian, F., Vatani Shoaa, J., Masoudi, M., Zahedi, S., \& Bakhshi, M. A. (2015): Psychosocial Factors and Musculoskeletal Pain Among Rural Hand-woven Carpet Weavers in Iran. Saf. Health Work, 6(2):120-127.

Coenen, P., Kingma, I., Boot, C.R., Twisk, J.W., Bongers, P.M., \& Van Dieën, J.H. (2013): Cmulative low back load at work as a risk factor of low back pain: a prospective cohort study. $L$ Occup. Rehabil., 23(1):11-18.

Dean, E., \& Söderlund, A. (2015): What is the role of lifestyle behaviour change associated with 5 non-communicable disease risk in managing musculoskeletal health conditions with special reference to chronic pain? BMC Musculoskeletal Disorders, 16:87

Farahani, A., \& Farahani, M. (2014): Relation between Postural Deformities of Vertebral Column and Resting Habits and Instruments Case Study: Middle Aged Females of Tehran. Bul.Appl.Spo. Phys., 13 (7):154-165 (Persian).

Grotle, M., Solberg, T., Storheim, K., Lærum, E., \& Zwart, J.A. (2014). Public and private health service in Norway: a comparison of patient characteristics and surgery criteria for patients with nerve root affections due to discus herniation. Euro. Spi. J.,23(9), 1984-1991.

Kadow, T., Sowa, G., Vo, N., \& Kang, J. D. (2015): Molecular basis of intervertebral disc degeneration and herniations: what are the important translational questions?. Clin. Orthop. Relat. Res., 473(6), 1903-1912.

Mikkonen, P., Heikkala, E., Paananen, M., Remes, J., Taimela, S., Auvinen, J., \& Karppinen, J. (2016): Accumulation of psychosocial and lifestyle factors and risk of low back pain in adolescence: a cohort study. Eur. Spine I., 25(2), 635-642.

Qiao, Z., Chen, L., Chen, M., Guan, X., Wang, L., Jiao, Y., Yang, J., Tang, Q., Yang, X., Qiu, X., Han, D., Ma, J., Yang, Y. \& Zhai, X.(2016): Prevalence and factors associated with occupational burnout among HIV/AIDS healthcare workers in China: a cross-sectional study. BMC pub. heal., 16:335.

Schaller, A., Dejonghe, L., Haastert, B., \& Froboese, I. (2015). Physical activity and health-related quality of life in chronic low back pain patients: a cross-sectional study. $\underline{B M C}$ Musculoskelet Disord, 19:16-62. 